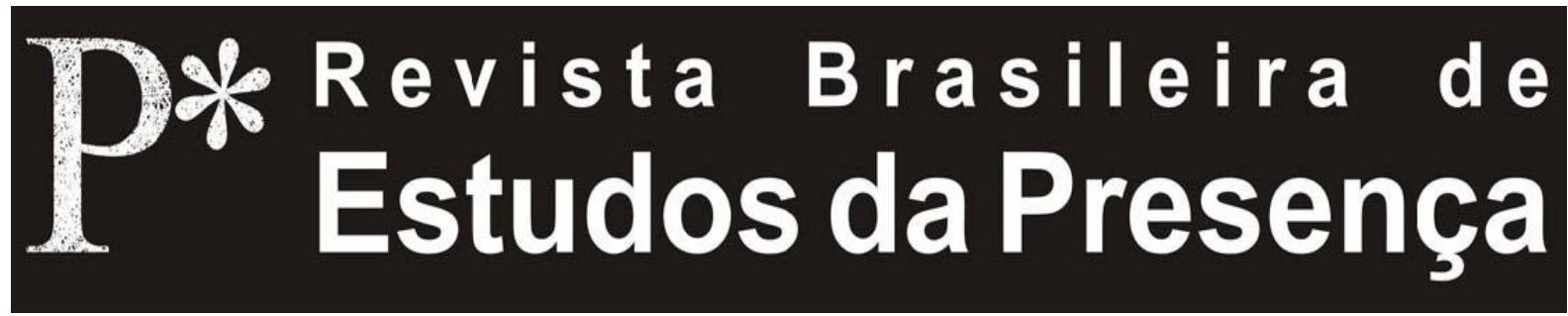

DOI - http://dx.doi.org/10.1590/2237-266037145

ISSN 2237-2660

\title{
Genética de um Reenactment em Jan Fabre
}

\author{
Giulio Boato \\ Università di Bologna - Bolonha, Itália
}

RESUMO - Genética de um Reenactment em Jan Fabre - Este artigo propóe um percurso seletivo através do processo de recriação de dois espetáculos de Jan Fabre: C'est $d u$ théâtre comme c'était à espérer et à prévoir (1982) e Le pouvoir des folies théâtrales (1984). O autor deste artigo - que acompanhou pessoalmente o trabalho da companhia de abril a julho de 2012 - escolheu se concentrar em particular sobre as sutis diferenças entre as duas versóes das obras, analisando as modalidades e as razóes das modificaçôes. O caminho traçado evidencia o trabalho do diretor e de seus performers, interrogando-se também sobre as noçóes de Genética Teatral e reenactment.

Palavras-chave: Jan Fabre. Genética Teatral. Reenactment. Ensaios. Teatro Pós-dramático.

ABSTRACT - Genetics of a Reenactment in Jan Fabre's Work - This article proposes a selective path through the process of recreation of two spectacles by Jan Fabre: This is theatre like it was to be expected and foreseen (1982) and The power of theatrical madness (1984). The author - who followed closely the work of the company from April to July 2012 - focuses on the small differences between the two versions of the works, analysing the modalities and reasons of the changes. The dissertation examines the work of the director and the performers, at the same time as it questions the notions of theatrical genetics and reenactment.

Keywords: Jan Fabre. Theatrical Genetics. Reenactment. Rehearsals. Postdramatic Theatre.

RÉSUMÉ - Génétique d'un Reenactment, chez Jan Fabre - L'article propose un parcours sélectif à travers le processus de recréation de deux spectacles de Jan Fabre: C'est du théâtre comme c'était à espérer et à prévoir (1982) et Le pouvoir des folies théâtrales (1984). Lauteur de cet article - qui a suivi personnellement le travail de la compagnie d'avril à juillet 2012 - a choisi de se concentrer en particulier sur les différences subtiles entre les deux versions des œuvres, en analysant les modalités et les raisons des changements. Le parcours suivi met en évidence le travail du metteur en scène et de ses performers, en s'interrogeant aussi sur les notions de génétique théâtrale et reenactment.

Mots-clés: Jan Fabre. Génétique Théâtrale. Reenactment. Répétitions. Théâtre Postdramatique. 
O teatro está sempre noutro lugar. Está na própria vida que anima a cena e que faz que ano após ano, espetáculo após espetáculo, o teatro não cesse de se renovar sem que nenhum estudo chegue a cristalizá-lo ou a desvendar suas leis fundamentais. E essa vida que a análise genética deve buscar preservar, a fim de evitar estas clivagens mortais que toda análise teórica do teatro carrega, os estigmas (Féral, 2008, p. 231) ${ }^{1}$.

Os estudos de Genética Teatral ${ }^{2}$ tornaram evidente aos olhos da crítica, nos últimos vinte anos, aquilo que já era muito claro para os artistas da cena: a apresentaçáo pública de um espetáculo, tal qual a ponta de um iceberg, é apenas um instante, táo sólido quanto efêmero, de um processo líquido ${ }^{3}$ que escorre em uma corrente cronológica. Além disso, a metáfora do iceberg, de agora em diante empregada, pode náo ser a mais apropriada: mais do que a única ponta visível de um grande trabalho submerso, as apresentaçóes de um espetáculo assemelham-se mais a um arquipélago de atóis, todos semelhantes e diferentes na sua repetiçáo. Se os encontros oficiais entre obra e público (o que chamamos de apresentaçóes) são ilhas dispostas por acaso no oceano do espaço-tempo, o pesquisador que deseja conhecer sua natureza profunda pode certamente visitá-las como turista, deixando-se encantar pela sua beleza inapreensível (está exatamente aí a experiência felizmente inocente do espectador), mas deve igualmente parar para se aprofundar sobre o terreno (geologia do espetáculo: analisar as diferentes fases de criação consultando os traços deixados - diários dos atores, documentos de vídeo, cadernos de anotaçáo dos atores, etc.), deve sobrevoar o arquipélago para dele conseguir uma visão global (monitoração do espetáculo: seguir a evolução da turnê, as eventuais modificaçōes da obra), e evidentemente interagir com a comunidade artística (entrevistar os criadores/intérpretes do espetáculo). Finalmente, o trabalho do analista teatral não pode se limitar à crítica, por mais profunda que seja, de um evento transitório e, em certo sentido, aleatório como uma das apresentaçôes da obra pode ser.

O teatro é uma arte viva que se constrói ao longo do tempo: longe de ser um ponto de final, o começo de um espetáculo é considerado por alguns diretores como um ponto de partida na vida da apresentação (Peter Brook, Jan Fabre, Robert Lepage, Bob Wilson). 
Cenografia, atuação, encenação: do menor detalhe à própria estrutura do espetáculo, tudo pode mudar durante as apresentaçóes de uma obra. Também o texto, que existe ou não enquanto elemento autossuficiente antes da criação do espetáculo, pode sofrer modificações importantes durante a turnê e tornar-se enfim (paradoxalmente) o encerramento do processo: "[...] a escritura é o evento final; encerra as apresentaçôes, sobre o papel ficam 'sublinhadas' e 'metabolizadas todas as variaçóes possíveis, destiladas em uma forma que será entregue à memória" (Monteverdi, 2004, p. 95) .

II

Foi indicado o arquivamento de um espetáculo (a cristalização da sua forma definitiva no papel) como a morte da obra viva, seu término natural. Mas, o evento teatral pode chegar a (sobre)viver muito além das previsões de seu criador: passado o tempo da turnê, mesmo após várias décadas, a obra pode ser retomada - pelo seu autor ou náo, por razóes as mais diversas - e reapresentada aos olhos do público (um público diferente, é claro, visto o salto temporal). Desde os últimos anos, a prática do reenactment ${ }^{5} \mathrm{em}$ arte contemporânea, sobretudo em dança, tomou uma dimensão significativa: em 1989, Mark Franko comentou a retomada de uma obra de 1962 de Dore Hoyer - célebre dançarina alemã que dançou com Mary Wigman pela sua compatriota Susanne Linke, afirmando que essa evidenciava a diferença entre o "artista original" e o "artista recriador", e notando que "[...] esse tipo de efeito de distanciamento é raro na reconstrução de danças históricas. Mas reciprocamente, a ideia de se reconstruir o trabalho de um predecessor tem sido rara, até tempos recentes, entre

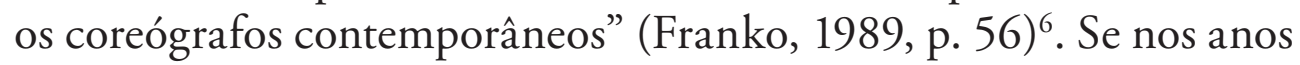
1980 o fenômeno ainda engatinha, seu desenvolvimento sucessivo seguirá depois uma verdadeira tendência da dança contemporânea: "[...] reconstruir e citar espetáculos históricos de dança, assim como transformar o palco de dança em um local para o arquivamento da performatividade da dança, tornaram-se importantes tendências na dança contemporânea" (Hardt, 2011, p. 27)7.

Em trinta anos, o reenactment impôs-se como prática estética, conseguindo confundir o campo artístico e o campo acadêmico: recolocar em cena antigas performances torna evidente a natureza performativa do fazer História, favorecendo, também no meio 
didático, a difusão de um modo de expressão incluindo leituras e documentaçóes apresentadas em cena. O passado tornou-se espaço de encenação para o presente, uma fonte de matéria já provada, à qual se pode recorrer para novas reediçóes.

Em certo sentido, pode-se ler o desenvolvimento do reenactment como um paralelo, no campo da prática, do surgimento da Genética nos Estudos Teatrais. A reprise de uma obra performativa muito após sua criaçáo - seja ela retrabalhada pelo próprio autor ou reencarnada por outra pessoa - náo é jamais uma cópia decalcada de uma dada forma estética. Assumir a responsabilidade de exumar um espetáculo significa encarregar-se de (re)descobrir seu modus vivendi: informar-se sobre seu processo de criação, definir as etapas de seu percurso, compreender suas razóes de ser no passado para daí identificar novas razões no contexto contemporâneo. Tudo isso só pode ser feito através de um percurso de pesquisa investigativa, vasculhando nos documentos de arquivo (rascunhos textuais, cênicos e visuais), consultando as notas de direção (quaisquer que sejam suas formas: escrita, desenhos, partituras, etc.), interrogando os criadores ou os primeiros espectadores, se possível. Sáo os mesmos procedimentos sugeridos pela Genética Teatral (Féral, 1997; 2008), ainda que orientados para outra finalidade: as pesquisas do especialista objetivam a sistematização crítica, as do artista, a produção poética.

\section{III}

A introdução bipartida (I e II), assim concebida para rapidamente recapitular as noçóes de Genética Teatral e de reenactment, é relativa à natureza particular deste artigo, que se pode definir como uma seleçấo de fragmentos de um processo de recriaçáo de dois espetáculos. Eu acompanhei a companhia Troubleyn/Jan Fabre durante o período de abril a julho de 2012 (das audiçóes dos atores até o começo do espetáculo), assistindo assim à reelaboração de dois espetáculos que consagraram Fabre como um dos atores mais singulares da cena teatral internacional: C'est du théâtre comme c'était à espérer et à prévoir ${ }^{8}$ (1982) e Le pouvoir des folies théâtrales ${ }^{9}$ (1984).

Minha presença nesse lugar foi fundamental para documentar o processo de trabalho, consequentemente, produzir uma análise tridimensional dos espetáculos, muito mais aprofundada do que a simples decifração de uma apresentação pública. A observação constante dos 
ensaios; a possibilidade de participar diretamente - em certos casos - do treinamento dos performers e da reelaboração da dramaturgia; as discussóes com o diretor, os atores e os colaboradores; o estudo dos documentos de arquivo (vídeos, transcriçóes textuais do texto, material de imprensa); e, evidentemente, a reelaboração pessoal dos elementos observados permitiram uma coleta investigativa das várias camadas que revestem a criação teatral.

$\mathrm{O}$ fato de essa produçáo ser um auto-reenactment - a reprise, por um autor, de seu próprio trabalho após três décadas - torna o objeto examinado muito interessante, do ponto de vista dos estudos genéticos: ao mesmo tempo em que conduzi um estudo direto sobre as atuais modalidades de trabalho do diretor flamenco, beneficiei-me do trabalho de pesquisa da companhia sobre suas primeiras encenaçóes, essas, a partir de então, recobertas pela poeira do tempo.

Este artigo pode ser lido, entáo, como uma metagenética: a análise de uma criação que busca ela mesma suas próprias origens. A documentação dos ensaios não poderá, assim, ser um testemunho fiel das modalidades criativas habituais de Jan Fabre, pois normalmente o diretor trabalha com seus performers por intermédio de improvisaçóes sobre temas, sem conhecer desde o começo a forma definitiva que terá o espetáculo ${ }^{10}$. No nosso caso, já antes dos ensaios, o artista controlava o aspecto final da obra ${ }^{11}$ e teve que trabalhar regressivamente, insuflando uma nova vida a uma forma estabelecida. Para consegui-lo, Fabre referiu-se a essas primeiras obras com um olhar crítico, recolocando-as em questáo como se fossem o trabalho de outra pessoa, e fazendo modificaçóes onde julgava necessário.

É exatamente esse percurso ao qual pude assistir e do qual posso dar conta. Tendo em vista a natureza breve deste artigo, mais do que um estudo sistemático dos processos de criação em Fabre, proponho aqui um percurso seletivo através desta crônica de uma recriação, privilegiando os aspectos que podem interessar mais aos estudos genéticos. A esse respeito, as disparidades entre as duas versóes das obras e as pequenas modificaçôes, cujas razões pude compreender, e acompanhar a elaboração, são esclarecedoras. Ao longo do processo de trabalho, das audiçôes às turnês (que enquanto escrevo só estão começando), os trinta anos que separam as duas ediçóes dos espetáculos inevitavelmente fizeram florescer um buquê de dissimilaridades que são, aos olhos da crítica, os testemunhos da evolução do percurso de 
um artista em particular, e da transformação da comunidade teatral na qual se insere em geral.

Selecionei, portanto, alguns exemplos disso que eu chamaria diferenças eloquentes: momentos férteis de transição entre o passado e o futuro, núcleos de reflexão em que a decisão do diretor, a atuação dos performers e, evidentemente, o acaso factual da prova sobre o palco geraram distorções, mudanças imprevistas, sintomas da indomável matéria viva teatral.

\section{IV}

A fim de melhor compreender os exemplos selecionados, é útil fornecer um breve quadro sobre os dois espetáculos que são objetos deste estudo. Tendo em vista a natureza não narrativa dos espetáculos, a atenção será concentrada mais sobre a história da criação do que sobre o enredo das obras. De fato, já que as condiçóes de criação diferem entre as duas ediçóes, esta introdução será um ponto de partida fundamental para compreender o sentido da análise.

Em 1982 estreia em Bruxelas C'est du théatre comme c'était à espérer et à prévoir, o segundo espetáculo teatral de Jan Fabre ${ }^{12}$. Por intermédio das audiçóes, ele escolhe oito pessoas entre as dezenas que haviam se apresentado. Somente uma entre elas é atriz profissional: "eu os escolhi pelo seu universo pessoal, sua mentalidade [...]. E, se trabalho com amadores, é porque não são deformados por tiques ou receitas teatrais" (Fabre in Laurent, 1983, s. p.). A nova companhia se retira por seis meses em um pequeno teatro da cidade de Harentals, a trinta quilômetros da Antuérpia. O ritmo é intenso: um dia de pausa para nove dias de trabalho. Diretor e atores improvisam sobre diversos temas, trabalham, comem e dormem juntos. Fabre concebe para eles um warming up ad hoc, misturando os exercícios de seu passado futebolístico com os conhecimentos adquiridos através das primeiras performances, assim como alguns elementos do teatro clássico. Alguns atores deixam a companhia após algumas semanas de trabalho, não aderindo aos métodos exigentes do jovem diretor. Os poucos que ficaram ao seu lado são obrigados, então, a recrutar novos atores nos bares da Antuérpia. Para remediar a falta de meios financeiros, durante as pausas a companhia se espalha pela cidade e toca nas ruas (Fabre, 2012). 
Ao término do período de ensaio, são obtidas quatorze horas de material, que serão reduzidas a oito: uma série de cenas/açóes inteiramente consagradas à tentativa de unir arte contemporânea e teatro, integrando à encenação a arte da instalação e a performance. Os temas abordados e os materiais utilizados no palco são geralmente citaçóes de obras de outros artistas plásticos do século XX, mestres espirituais do diretor.

Graças ao sucesso obtido com C'est du théatre, Fabre encontra produtores para o projeto seguinte. Algumas centenas de atores e dançarinos se apresentam nas audiçóes para Le pouvoir des folies théâtrales, mas os quinze selecionados (todos têm entre 20 e 30 anos) são ainda, na maioria, não profissionais. A escolha é mais ampla, mas o que Fabre chama de raiva, ou paixão, continua como critério número um: "[...] quando tiver que escolher entre a raiva e a técnica, sempre escolherei aquele que tem raiva" (Fabre; Boato, 2012, entrevista) ${ }^{13}$. Novamente a companhia se retira para um pequeno centro e trabalha intensamente durante quatro meses, com as mesmas modalidades das sessóes anteriores de ensaios. O espetáculo (que, como C'est $d u$ théâtre, é construído a partir de quadros cênicos independentes que se superpóem) se coloca como homenagem e crítica ao teatro burguês, à ficção cênica e às convençóes teatrais, levadas à cena por intermédio do filtro das narrativas fantásticas, entre as quais $O$ príncipe sapo, $A$ roupa nova do rei $\mathrm{e} A$ bela adormecida. O espetáculo estreia em 11 de junho de 1984, no Teatro Carlo Goldoni, na programação da Bienal de Veneza (durante a qual Fabre apresentará igualmente uma série de desenhos). Após Veneza, o espetáculo segue seu caminho para uma turnê mundial que levará dois anos.

V

Troubleyn/Jan Fabre é atualmente uma das mais importantes companhias da Bélgica ${ }^{14}$. Para as novas ediçóes de C'est du théâtre e de Pouvoir, Fabre fez audiçóes não só na Antuérpia, mas também em Paris, Roma, Atenas e Zagreb, examinando um leque de cerca de 1400 atores, dançarinos e performers. É evidente que a qualidade dos performers atuais é nitidamente superior àquela de seus predecessores, dos quais um bom número não eram profissionais. Em compensação, o que é mais difícil de achar nessa nova lavra é essa cólera, essa necessidade absoluta de estar em cena: "[...] estou 
procurando pela verdadeira raiva, 'eu quero morrer por isso': eles a sentiam naturalmente naquela época, eles eram amadores no sentido de que eles amavam a beleza" (Fabre; Boato, 2012, entrevista) ${ }^{15}$.

O tempo de adaptação dos novos atores foi muito mais breve do que na primeira versão: em oito semanas foram paralelamente preparados os dois espetáculos, baseando-se em vídeos de arquivo e nas notas de direção originais. Mas Fabre, como se sabe, pertence àqueles diretores que náo colocam jamais um ponto final em suas encenaçóes: "Eu ensino ao meu grupo: a última performance será a primeira" (Fabre; Boato, 2012, entrevista) ${ }^{16}$. Por essa razáo, o material de arquivo não é nunca plenamente confiável. Para complicar ainda mais, Fabre muda frequentemente os papéis de seus atores, às vezes durante a turnê, pouco antes de entrar em cena. O diretor exige que cada ator conheça todo o espetáculo e possa assumir qualquer um dos papéis: "Eu modifico as pessoas para torná-las alertas, despertas, para evitar a armadilha do automatismo" (Fabre; Boato, 2012, entrevista $)^{17}$. A instabilidade da forma é condição original para C'est $d u$ théâtre: durante o primeiro ano de apresentação (mal recebido pela crítica e pelo público), diretor e atores, ainda sem experiência e em permanente busca de novas soluçóes, tentaram inúmeras variantes. É por essa razão que o vídeo de arquivo e a própria encenação são apenas dois traços em uma constelação de pequenas variantes efêmeras, que se dissolvem ao mesmo tempo em que os espectadores saem, ao fim de cada apresentação.

Uma parte do trabalho foi feita igualmente sobre a base de lembranças pessoais do diretor e de sua inseparável assistente, Miet Martens, que integrou a companhia um mês antes da turnê de Pouvoir des folies théâtrales e acompanhou as outras sessenta apresentaçóes pelo mundo. Para enfrentar a parcial incerteza da memória e do suporte documental, Fabre e sua equipe tomaram cuidado em ajustar alguns detalhes durante o processo de ensaio. Acrescentaram alguns textos de Pouvoir, modificaram algumas traduçóes (o texto é sempre multilíngue) em relação com os conhecimentos linguísticos dos novos performers e propuseram algumas ligeiras variantes para C'est du théâtre. Nesse espetáculo em particular, a partitura cênica não se baseou escrupulosamente na original: se a estrutura de base permanece (dificilmente modificável quando se sabe que cada cena está relacionada à seguinte), constata-se o remanejamento de certas 
ações internas, a mudança de pequenos detalhes para inspirar os atores e dar um novo fôlego a um trabalho que náo deve de modo algum se assemelhar a uma pálida cópia privada de conteúdo. Assim, a versão 2012 prevê um ator a mais em relação ao elenco original: para nada perder das preciosas diferenças das qualidades de interpretação dos novos performers, o papel de uma das primeiras atrizes (Els Deceukelier, uma das musas do diretor) foi dividido entre duas novas dançarinas ${ }^{18}$.

O modus operandi do diretor (variar os detalhes das ações conservando a estrutura do espetáculo) encontra um paralelo na maneira de atuar de seus atores: a organização dos movimentos é extremamente precisa, o espaço é milimetricamente medido e cada posição assinalada no chão por um adesivo (rigorosamente preto como o palco, de modo que apenas os atores consigam vê-lo e reconhecêlo). No entanto, essa rígida estrutura é criada especialmente para ser animada pela personalidade do ator, pela sua inventividade e sua vitalidade. A cada noite os atores devem levar variantes mínimas às suas açôes, reencontrar sua razão de ser e sua necessidade de estar em cena. A originalidade deve passar através da obrigaçáo para poder brilhar: "atrás das nuvens, o sol brilha" (Scholde, 2007) ${ }^{19}$, eis o que está escrito sobre uma das paredes do pátio interno de Troubleyn.

VI

"Na primeira vez em que eu o assisti, fiquei muito emocionado" (Fabre; Boato, 2012, entrevista) ${ }^{20}$, revela Fabre sobre o primeiro ensaio sem interrupção de Pouvoir des folies théâtrales, em maio de 2012. A primeira sessão de trabalho era sob forma de master class: trinta performers (atores e dançarinos) trabalharam durante duas semanas sobre trechos de cenas oriundas dos dois espetáculos. Esses dez dias iniciais eram destinados a selecionar os quinze atores definitivos e a produzir improvisaçóes destinadas a integrar determinadas cenas. Mesmo se os performers não conhecessem o espetáculo que montariam, eles evocaram sobre o palco a alma das duas obras encarnando as diretrizes do diretor. Sendo os dois espetáculos advindos de uma mesma trilogia (os três primeiros espetáculos de Fabre contêm a palavra teatro no título, afirmando a vontade de investigar as características da arte teatral) e sendo um o filho do outro (vista a contiguidade temporal e a partilha de certos temas), os exercícios/improvisaçóes do 
master class puderam alimentar-se das duas encenaçóes, misturando os elementos e alterando as condiçóes. Esse trabalho inicial - duro e apaixonante para os performers, conscientes de estar na última etapa de uma seleção - permitiu o acúmulo de um material precioso para a seção sucessiva, os ensaios efetivos dos espetáculos.

É, de fato, somente após a seleçáo definitiva dos atores que começou o trabalho sobre o texto performativo original, a reelaboraçáo da velha estrutura dos espetáculos por intermédio dos corpos de jovens performers - a maior parte deles náo tendo ainda nascido na época das turnês anteriores, nos anos 1980. Ainda que a ordem cronológica instaure C'est du théatre como o primeiro, os ensaios começaram por Le pouvoir des folies théâtrales ${ }^{21}$. Toda a estrutura, da primeira à última cena deste último, as quatro horas e meia que durava o espetáculo, foram completadas em quatro semanas. Entre todas as cenas do espetáculo, a quarta (definida como emperor's clothes durante os ensaios) é aquela que foi mais modificada em relação à versão original. Eis o resumo essencial.

Em duplas, oito atores entram em cena e se posicionam em linha no centro do palco. Sob a direção orquestral de dois reis nus - que fazem de seus cetros uma batuta -, os performers alinhados trocam beijos no ar, ritmando em coro a famosa marcha nupcial wagneriana. Terminado o parêntese musical, começa a aula de História: de Senhorita Júlia até Esperando Godot, os títulos dos principais espetáculos teatrais da primeira metade do século XX são revistos como uma lista telefônica, acompanhados de sua data e local da primeira apresentação. Mas o texto é somente o fundo sonoro da açáo: os oito atores passam meia hora tirando e vestindo a roupa para mostrar suas vestimentas aos reis. Quatro deles tiram completamente a roupa e vestem maravilhosos trajes invisíveis, que exibem ao soberano na boca de cena, enquanto os outros se exibem ao imperador atrás, conservando seus trajes reais. A cada repetiçáo do texto (que dura alguns minutos) os quartetos trocam de posição, cruzando-se na linha central, uns tirando a roupa, outros se vestindo novamente. 


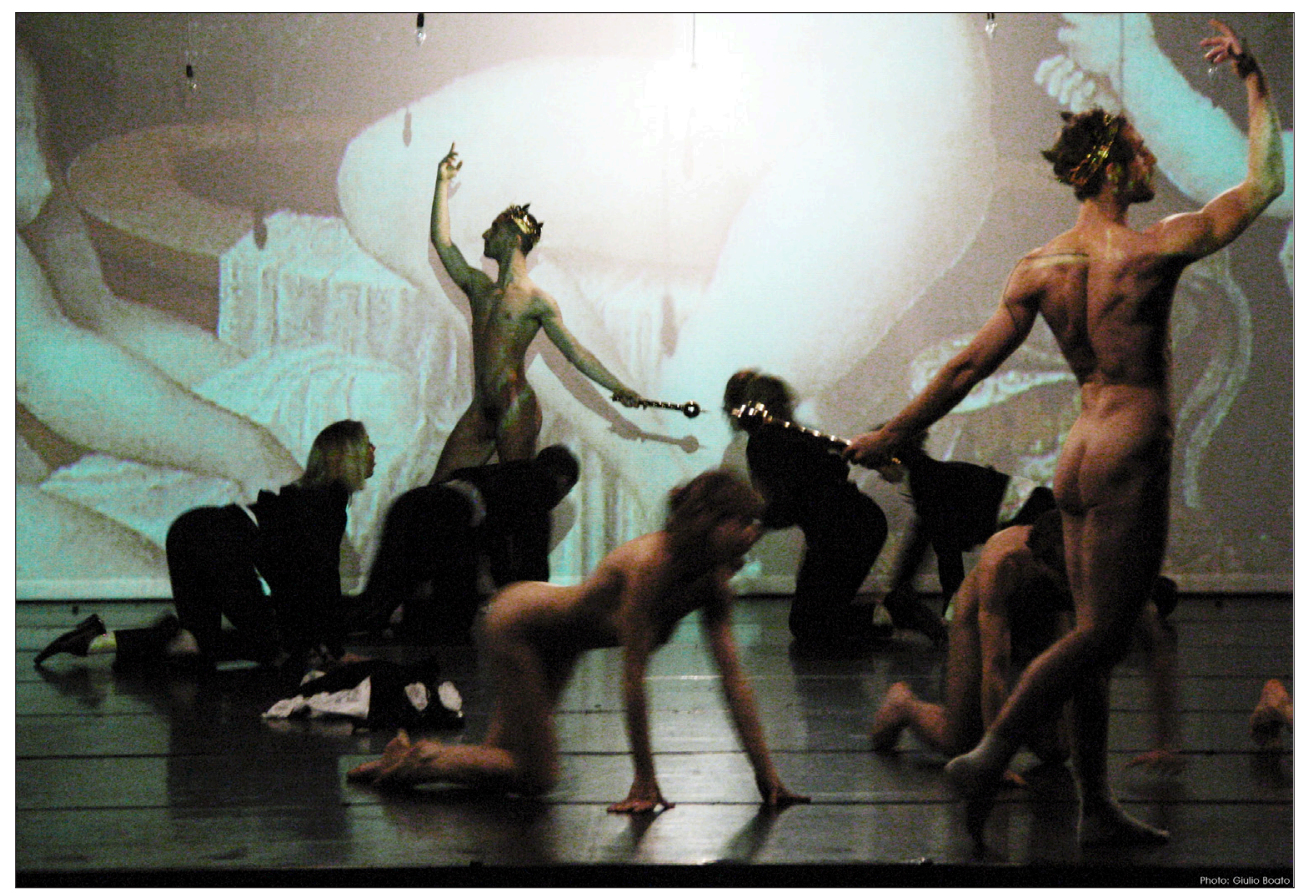

Foto 1: Giulio Boato (C. Performers: Georgios Kotsifakis, Gilles Polet (em pé), Maria Dafneros, Melissa Guerin, Nelle Hens, Carlijn Koppelmans, Pietro Quadrino, Kasper Vandenberghe. Performance: Le pouvoir des folies théâtrales, cena 4.

A cena é extraída do conto A roupa nova do rei, de Andersen, que pode ser lido como uma sátira da hipocrisia, relacionada ao medo de contradizer o poder. Fabre faz daí, ao contrário, um modelo da própria natureza do teatro: o rei e todos os seus súditos não apenas são enganados pelos falsos tecelóes que lhes vendem trajes inexistentes, como, além disso, eles aceitam ser enganados. Fingem acreditar naquilo que não veem, por medo de serem mal julgados. Do mesmo modo, o espectador teatral quer ser enganado pela representação: entra em um lugar que sabe ser dedicado à ficção e aceita as regras. $O$ conto de fadas age, então, como matéria para principalmente falar - ao teatro, do teatro. A estrutura narrativa da fábula é posta de lado para focalizar a atenção sobre a ação principal, repetida em loop: mostrar e vestir trajes inexistentes.

A versão que descrevi é, no entanto, muito diferente da versão anterior: em 1984 os atores mostravam ao rei seus trajes (verdadeiros ou imaginários), mas jamais tiravam a roupa completamente, nem fingiam vestir trajes invisíveis. Além disso, não havia texto, enumeravam uma sequência de cifras, de um a oito, como se fosse uma aula de balé. A situação era, de fato, uma cópia da cena quinze de 
C'est $d u$ théâtre, na qual oito atores mostravam ao público a parte do corpo que achavam ser a mais bonita, e depois a mais feia (sem jamais se despir integralmente). A configuração espacial das duas cenas era quase idêntica: no lugar dos reis, em C'est du théatre, havia duas lâmpadas de pé, à luz das quais os atores indicavam a parte corporal adorada/detestada. O tique-taque de um metrônomo escandia o tempo no qual os atores contavam até oito (em inglês, holandês, alemão e francês).

A versão de Pouvoir de 2012 substituiu tal conteúdo por um texto (do qual trataremos adiante), mas, sobretudo, modificou a partitura das açôes. Os performers que mostram os trajes invisíveis devem, antes de tudo, vesti-los: várias semanas de trabalho foram necessárias para atingir a qualidade de pantomima do ato de se vestir. Esse substantivo está grifado porque seu uso é impróprio: Fabre não quer apresentar a seu público uma cena de pantomima, mas uma ficção verossímil. A diferença é sutil, mas fundamental: os atores não devem mostrar uma profissão ou um personagem, mas executar uma ação, o mais fielmente possível: "do simples movements, but clear!", sugere o diretor durante os ensaios. A carne se faz texto: o corpo nu descreve o traje através dos pequenos movimentos impostos. A manifestação dos efeitos revela a causa dessa exigência: o trabalho de imaginação do ator se concretiza no corpo (andar, postura) e se evapora, entáo, no espírito do espectador em emaranhados de tecido a colorir. O performer deve ter claro em mente a forma do traje que ele assumirá, deve estabelecer os detalhes e avaliar seu peso: depois do ato de se vestir é previsto, com efeito, o desfile diante do rei.

Mas, as dificuldades para os atores não param aí: a cada round os modelos devem adotar um método de demonstração diferente. Durante os ensaios, numerosas improvisaçóes de grupo (iniciadas com trinta performers já durante o master class) permitiram ao diretor escolher as descobertas mais bem sucedidas: há o desfile em forma de striptease, aquele com forte entonação melodramática, há o ateliê de costura e a briga de cachorros. A cada nova repetiçáo do ciclo textual o showreel das roupas novas do rei torna-se uma ocasião para organizar pequenas cenas cômicas: o grupo de performers nus encanta o rei (nu como eles) na boca de cena, enquanto o restante dos performers, vestidos, divertem o rei no fundo. Para complicar, o texto deve fluir de boca em boca como um fluxo contínuo e vivaz 
de datas, nomes e títulos. A cena emperour's clothes permanece como uma das cenas mais difíceis para os atores: até que tenha havido o impacto desejado sobre o público, não se admite nenhum erro. Roupas imaginárias, desfile previsto e texto devem se integrar e se estimular respectivamente em um turbilhão sempre mais frenético, banhado pelas cascadas de notas de Wim Mertens (1984) ${ }^{22}$.

"Pletora" (Lehmann, 2002, p. 142), "hipertrofia" (Lehmann, 2002, p. 137), "superposição de signos" (Lehmann, 2002, p. 139), sugere Lehmann no seu Postdramatisches Theater (Lehmann, 2002). Confrontado com essa cena, o público se reconhece como o alvo de uma quantidade inadministrável de informações: entre as longínquas reminiscências infantis do conto de Andersen, a atenção ao jogo cênico das roupas invisíveis e a irritaçáo causada pela repetição interminável da aula de história do teatro (acompanhada pela música minimalista), os espectadores sufocam em suas poltronas. Se a visão primeira da cena permite captar com dificuldade todos os estratos de sentidos superpostos, esta análise pode se permitir recorrer ao pente fino da memória (e, portanto, de todo modo seletivo) e se concentrar separadamente sobre cada um desses aspectos. Ao seguir o fio condutor das diferenças entre as duas versóes do mesmo espetáculo, um ponto nodal permanece. A cena que acaba de ser examinada oferece o exemplo mais funcional para a compreensão das modalidades de escritura empregadas na construção e reconstrução dessa obra.

\section{VII}

Em Le pouvoir des folies théatrales, entre as falas pronunciadas em cena, exceto os breves fragmentos de livreto de ópera lírica (sempre cantados), não encontramos nada além de datas, cidades, títulos de espetáculos teatrais/performances/dança e nomes de diretores/ dramaturgos/coreógrafos. De L'Anneau de Nibelungen de Wagner, que abre o espetáculo quase em forma de manifesto, a lista segue até os anos $1980^{23}$. Durante as quatro horas e meia de espetáculo, o texto se compóe de cinco cenas ${ }^{24}$, dividido entre os diferentes atores como se fosse uma conversa, e repetido, na maior parte das vezes, por cerca de 20 minutos.

Qual é o objetivo da escolha de Fabre? Rememorar o passado, homenagear a tradição, fazer o esboço de um manual, irritar os espectadores, revolucionar a prática teatral. É um beijo venenoso no 
teatro, uma declaração de amor que se torna declaração de morte. Fabre faz do espetáculo, que o inicia na Bienal de Veneza, um manifesto de intençôes: declara suas próprias origens, honra seus próprios mestres e propóe algo que os opóe abertamente a ele ${ }^{25}$. Se podemos ler na operação de Fabre uma piscadela à história do teatro, deixemos falar as más línguas que veem nesse texto uma irônica lista telefônica, degradando a imagem dos mestres do século XX, reduzindo-os a um simples flatus vocis. Sendo assim, se observarmos, a descoberta funciona: em um oxímoro de humildade e de deboche, em junho de 1984 o jovem artista flamenco se impóe na cena internacional como uma novidade imprevista, com uma irritante, mas sem igual, qualidade.

Se C'est du théatre manteve os textos quase inalterados entre a primeira e a segunda versão (exceção feita para algumas traduçóes, feitas também em funçáo das origens linguísticas dos novos performers), Le pouvoir sofreu alguns adiamentos. Nos anos 1980, as dificuldades para focar informaçóes precisas sobre as datas e lugares das estreias dos espetáculos conduziram a alguns erros na lista que foi revista e corrigida pela equipe que trabalhou no reenactment. Além disso, o diretor quis acrescentar um novo texto que homenageia as vanguardas históricas, ausentes na primeira versão (que saltava de Wagner a Brook). A cena quatro apareceu como o lugar ideal para inserir o novo texto, composto pela nova equipe à maneira da antiga. Propomos como exemplo exatamente essa nova cena, cujas modalidades de construçáo examinaremos rapidamente:

1 Actor 1: Eighteen hundred seventy-nine. A Doll's House.

Actor 2: Nora oder Ein Puppenheim! Hendrik Ibsen.

Actor 5: Ibsen? Eighteen hundred seventy-six, The Pretenders, SaxeMeiningen Compagnie, Berlin.

Actor 4: Mille-huit-cent quatrevingt-treize (1893), Fröken Julie, August Strindberg.

5 Actor 6: Mademoiselle Julie, André Antoine, Théâtre Libre, Paris Actor 3: Théâtre de l'Oeuvre, Paris. Mille-huit-cent quatrevingt-seize (1896)?

Actor 8: Achttienhonderdzesennegentig (1896).

Actor 6: Ubu.

Actor 1: Ubu Roi! Alfred Jarry

10 Actor 7: Eighteen hundred ninety-eight (1898), The Seagull, AntonTchekhov Actor 2: Constantin Stanislavski

Actor 5: Stanislavski? Nineteen hundred eleven, Hamlet, Gordon Craig. Actor 3: Neunzehn hundert zwölf (1912)!

Actor 4: Nineteen hundred eleven. Art theater, Moscow.

Actor 1: Moscow? Maurice. 
Actor 5: Maeterlinck!

Actor 7: Nineteen hundred six, Soeur Beatrice, St. Petersburg.

Actor 6: Nineteen hundred nine.

Actor 2: Neunzehn hundert neun. Oedipous Rex.

20 Actor 3: Reinhardt, Max! Zircus Schumann, Berlin.

Actor 8: Vsevolod Meyerhold, Nineteen hundred twenty-two, Actor's

Theater, Moscow.

Actor 6: Le Cocu.

Actor 7: Le Cocu?

Actor 6: Le Cocu magnifique!

25 Actor 5: La biomécanique!

Actor 3: Arnold Schönberg, Erwartung, Prague, neunzehn hundert vierundzwanzig.

Actor 8: Der Verfremdungseffekt! Neunzehn hundert achtundzwanzig (1928), Bertolt Brecht.

Actor 5: The Beggar's Opera?

Actor 1: Die Dreigroschenoper!

30 Actor 6: Kurt Weill, Mahagonny-Songspiel, Baden-Baden, 1927.

Actor 2: Negentienhonderdeenenveertig (1941), Zurich.

Actor 3: With actors in exile: Mutter Courage!

Actor 4: Mille-neuf-cent trente-cinq.

Actor 8: Negentienhonderdvijvendertig.

Actor 7: Antonin Artaud!

Actor 6: Artaud! Artaud!

Actor 5: Les Cenci, Théâtre des folies, Paris.

Actor 1: Le Théâtre de la Cruauté.

Actor 4: Le Théâtre de l’Absurde! Mille-neuf-cent cinquante (1950).

Actor 3: Beckett.

Actor 7: Ionesco! Eugène Ionesco.

Actor 2: Samuel Beckett, Nineteen hundred fifty-three, En attendant Godot, Théâtre de Babylon, Paris.

Actor 6: Théâtre des Noctambules, Mille-neuf-cent cinquante, $\mathrm{La}$ Cantatrice Chauve.

Actor 8: Nineteen hundred fifty-one: La Leçon! ${ }^{26}$

O texto é organizado como um encaixe de blocos modulares de sentido, compostos de data-artista-obra-lugar, às vezes distribuídos sobre várias réplicas, e entáo divididos entre vários atores. Como em C'est du théâtre, em Le pouvoir vence igualmente o princípio do plurilinguismo, justificando-se, nesse caso, pela fidelidade à língua original dos espetáculos/atores citados. As ligaçôes entre as réplicas são combinadas por complementos do bloco semântico (linhas 9-10), por afinidades de argumentos (linhas 24-25), por repetiçóes sonoras (linhas 19-20), por jogos de palavras (linha 15) e por simples traduçôes (linhas 1-2) ou por correçóes (linhas 12-14). A história do teatro torna-se um quebra-cabeça, dada com o qual se pode jogar e se divertir. Para que o texto náo seja entediante - vista a longa repetiçáo 
do breve fragmento-lista - os atores devem trocar as réplicas com vivacidade, como em uma conversa normal. É evidente que qualquer conteúdo psicológico está ausente do texto, mas os performers devem se esforçar a cada round para encontrar novas entonaçóes, deixando-se guiar pela açáo cênica, permanecendo vigilantes e abertos diante dos eventos para continuamente estabelecer novas relaçóes entre eles. $\mathrm{O}$ desejo de Fabre, no que diz respeito à interpretaçáo do texto (diferentemente de C'est du théâtre, em Le pouvoir é pedido aos performers que atinjam um esforço de inovação constante na atuaçáo durante a repetiçáo do texto), nos permite definir a relaçáo particular entre liberdade e determinismo que caracteriza a atuação dos atores. Apesar da estreita grade formal (o texto de um lado, a ação/espaço de outro) que obriga os performers a seguir à risca uma série de indicaçóes precisas, como se fossem marionetes privadas de vontade própria (a sombra de Gordon $\mathrm{Craig}^{27}$ assombra os sonhos de Fabre), a eficiência da cena náo pode ignorar a capacidade de invenção, até mesmo de improvisação, inteiramente dependente dos atores. A disciplina liga os corpos ao espaço, a vontade (de sobrevivência) lhes dá asas: os performers demonstram sua força justamente em condição difícil, sempre inventando novas saídas de emergência da gaiola visual/sonora. O texto-lista é um exemplo esclarecedor do esforço pedido para semelhante execução repetitiva e mecânica de um conteúdo vazio de sentido, devendo ser preenchido de vitalidade pelos performers para tornar-se teatral.

\section{VIII}

O processo de criação de um espetáculo não termina, como vimos, nos ensaios. Para prová-lo, acrescentarei a esse percurso fragmentário através do reenactment de Fabre uma história preciosa. As estreias de 2012 de C'est du théâtre comme c'était à espérer et à prévoir e Le pouvoir des folies théâtrales aconteceram na Áustria, país no qual a lei proíbe a presença de animal livre em cena. No entanto, a presença de animais vivos é uma constante nos espetáculos de Fabre: em C'est $d u$ théâtre, os atores se veem dividindo o palco com cinco pequenos papagaios e três tartarugas. Os papagaios são os convidados de honra da cena cinco: empoleirados no indicador de cinco indivíduos de olhos vendados com fita adesiva, as frágeis aves se veem guiando os cegos, presas às suas camisas com um cordão. Os atores se orientam 
sobre o palco, cada um recitando um breve texto evocando a morte e o cemitério (escritos pelos atores do elenco original). $\mathrm{O}$ texto é dito batendo-se ritmadamente na boca com a máo deixada livre para dar ao som da voz uma reverberação própria de megafone. Para enfeitar ainda a cacofonia, o som agudo de uma serra circular - elaborada no sintetizador pelo compositor Guy D. Drieghe, que é responsável pela totalidade dos efeitos sonoros do espetáculo - soa nos ouvidos dos espectadores, transmitindo-lhes uma desagradável sensação para além do audível, atacando diretamente o corpo, atravessando o tímpano para fazer vibrar os ossos do crânio. Ao repetir seus textos em uníssono, os atores de olhos vendados colocam no chão os pequenos papagaios e se procuram pelo tato no centro da cena, para juntos atar o cordáo de seus guias: os cinco papagaios pisam forte e resmungam no cháo, náo podendo voar por causa da teia de aranha que os prende. Antes de sair de cena, cada ator retira sua camisa e cala seu papagaio jogando-a sobre ele. $\mathrm{O}$ silêncio, finalmente, reina.

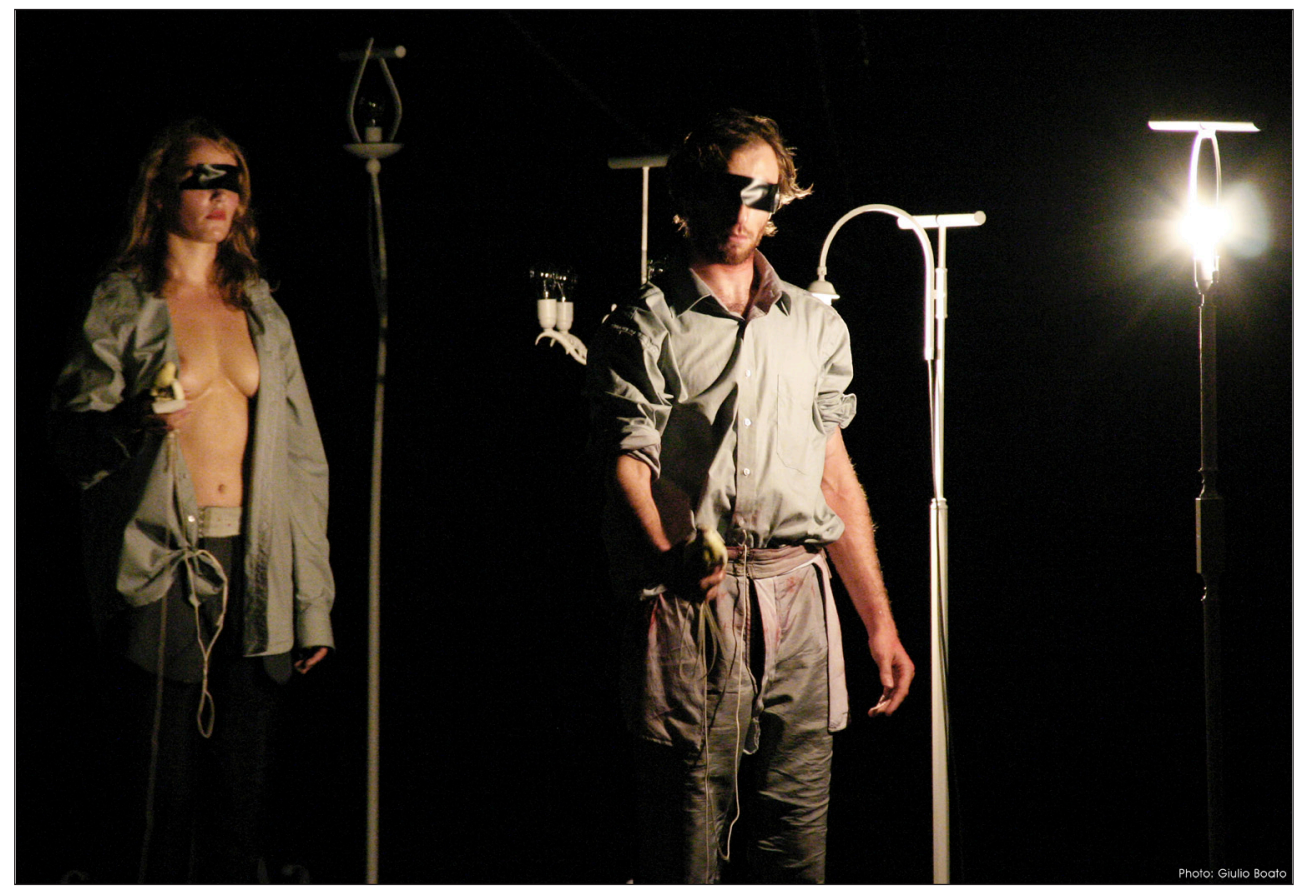

Foto 2: Giulio Boato (C). Performers: Pietro Quadrino, Merel Severs. Performance: C'est du théâtre comme c'était à espérer et à prévoir, cena 4.

Tendo em vista a proibição austríaca, Fabre decidiu substituir os pequenos papagaios por velas acesas instaladas em gaiolas grandes e portáteis. Visualmente, a cena de substituição era nitidamente mais graciosa que a original: as velas projetavam suas sombras vibrantes 
sobre o pano do fundo, os pequenos pontos de luz que brilhavam no escuro tornavam-se inúteis tochas para os cegos habitando este mundo. A cena perdia, no entanto, seu caráter perturbador. De fato, a presença de aves vivas tem um valor icônico que não pode ter também qualquer objeto inanimado: "[...] quando eles caminham com as aves presas ou largam duas tartarugas, é triste como um conto de fadas" (Scali, 1983, s. p.). O animal é incontrolável e imprevisível; pela sua fragilidade e sua inocência, estabelece imediatamente uma relação de empatia com o público. A visão de aves que não podem voar, únicos olhos totalmente abertos para um mundo de cegos, dá à cena uma fragilidade desconfortável que induz o espectador a se sentir quase culpado (senão ofendido). $\mathrm{O}$ animal náo é julgado com base em uma açáo que ele teria que cumprir (tecnicamente, os pequenos papagaios não têm nenhuma missão, diferentemente dos atores). $\mathrm{O}$ efeito perturbador sobre o espectador é causado pela simples presença das aves. A copresença do homem e do animal estabelece de imediato uma relação de força: nesse caso, o animal é visto como estando à mercê do homem, aí podendo estar incluídos todos os eventuais sentimentos de culpa, aversão, cólera, tristeza. Mesmo se em cena não aconteça quase nada, o efeito sobre o espectador está garantido, e não pode ser substituído por nenhuma vela:

Personagens, vendados por um esparadrapo preto, com papagaios presos a um fio e dizendo alternadamente, em inglês, flamenco, francês, alemão, "eu amo a vida", "quero continuar vivendo", "muitos amigos estão lá", "quem vai vir me ajudar?" apresentam talvez a mais precisa traduçáo cênica que se pode fazer de uma viagem aos infernos (Dumond, 1983, s. p. $)^{28}$.

A cena atrofiada das aves certamente não é o único exemplo da dificuldade de apresentar os animais em cena: durante os meses de criação do espetáculo, em 1982, uma das muitas cenas suprimidas previa a introdução em cena de dezoito coelhos ligados entre si por longos elásticos, que correndo e saltando sobre o palco aprisionariam os atores em uma teia movente. A cena foi abandonada em razáo dos componentes aleatórios excessivos, que impossibilitariam que os atores agissem e controlassem os eventos.

O trabalho com animais vivos afirma a escolha de submeter a encenação teatral às leis do acaso (e, então, à não reprodutibilidade do gesto), ainda que buscando certo controle da imprevisibilidade do real no evento performativo. O primeiro grande espetáculo de Jan 
Fabre, C'est du théâtre é a tentativa de contaminação das artes da performance pelas convençóes teatrais, servindo-se das modalidades artísticas do século XX para criar uma forma híbrida entre cena e instalação, recitação e ação.

IX

A reflexão sobre o interesse, por parte de Fabre, pelos animais, nos permite fazer a ligação com esta última parte do artigo: um rápido testemunho das sessóes de ensaio que os atores seguiram durante dois meses de ensaios. Em cinco dias de trabalho por semana, dois aquecimentos eram dedicados ao ioga ${ }^{29}$, dois ao kendo ${ }^{30}$ e uma manhã era ocupada por um singular treinamento de ator diretamente conduzido pelo diretor. As três tipologias de exercícios se equilibram reciprocamente, fornecendo aos performers ferramentas indispensáveis para sobreviver sobre o palco de Fabre. No quadro de um estudo genético, o método de ensaio dos atores é um dos maiores interesses do pesquisador teatral, pois permite se aproximar das modalidades de trabalho que está na origem dos espetáculos. Além disso, esse aspecto é particularmente importante em Fabre, que se ocupa pessoalmente da formação de seus performers.

No seu precioso estudo sobre a direçáo de ator no teatro contemporâneo, Sophie Proust dedica um capítulo à diferença entre a direção de atores e a formação de atores, identificando uma clara linha de demarcação entre as duas práticas: "[...] um diretor deve trabalhar com um ator já formado para inventar uma atuação em conjunto, e não remediar uma falta de formação ou se preocupar com a progressão pessoal de um indivíduo na sua carreira teatral" ${ }^{11}$ (Proust, 2006, p. 63). Sem querer contestar a validade geral dessa afirmação, é preciso questioná-la em relação ao caso do diretor flamenco: Fabre escolhe sempre atores de origem bem diferente (dança, teatro, canto lírico), que náo possuem naturalmente, de modo algum, os mesmos conhecimentos técnicos. As sessóes de ensaio guiadas pelo diretor servem então para dar uma base comum aos performers, a fazê-los avançar em um percurso de aprendizagem que é relativo ao trabalho do artista, para qualquer dos espetáculos. Em relação a isso, alguns dos seus intérpretes o acompanham na duração, interpretando vários espetáculos e tornando-se, assim, Guerreiros da beleza (denominação que Fabre dá a seus performers fiéis). É, portanto, evidente, nesse 
caso em particular, que a intenção pedagógica não é estranha à direção de ator.

Ao omitir aqui essas sessóes de kendo e ioga (seria preciso dedicar um artigo inteiro a isso), dedicarei estas últimas páginas ao curso que Fabre dá a seus atores a cada semana: um percurso performativo sui generis entre homem e animal, que faz dos humanos animais do palco e dos animais os reis da cena.

Os animais foram sempre uma fonte de inspiração para o artistadiretor. Nascido em uma família que possuía muitos animais, inclusive exóticos, foi educado desde sua mais tenra infância a observá-los e estudá-los (várias foram as visitas ao zoológico da Antuérpia na juventude, caneta bic na máo para desenhar os corpos dos bichos em movimento ${ }^{32}$ ). Em vários desenhos do artista, o homem e o animal se misturam, integrados um no outro, como suporte mútuo, na utópica realização de um ser invencível, blindado como um inseto, ágil como um guepardo, leve como um pássaro ${ }^{33}$.

Do ponto de vista do trabalho do ator, o interesse do diretor pelos animais é motivado pelo senso de ritmo deles, pela sensibilidade elevada, ao mesmo tempo similar e diferente da humana, e pela capacidade de adaptaçáo e de metamorfose: todas as qualidades que o performer de Fabre deve desenvolver. Fabre se insere em uma longa tradição: já nas primeiras décadas do século XX, Meyerhold assinala como ponto de partida de suas reflexóes sobre o ator biomecânico a recuperação do movimento animal.

Um leão em cativeiro se movimenta exatamente no ritmo do metrônomo e repousa a pata exatamente lá onde inicialmente ela estava. Essa repetitividade não é sinal de um ser obtuso, nem de simples repetitividade, não, é sinal de uma constante tensão de viver segundo um ritmo. [...] Definiremos o ator como um 'magnífico animal' que quer mostrar sua própria arte. [...] O novo teatro nascerá, então, da interação entre natureza e corpo humano, o que significa a fusão entre o Homem e a parte animal que há nele (Meyerhold, 1993, p. 54) ${ }^{34}$.

Náo por acaso, as sessóes de ensaio/aquecimento conduzidas por Fabre consistem na imitaçáo física e sonora de diferentes animais: em noventa minutos, os performers encarnam sem descanso uma imaginária evolução da espécie, dando seus primeiros passos em quatro patas como um bando de gatos (homenagem aos exercícios criados por Jerzy Grotowski), se lavando e miando, aquecendo 
os músculos e as cordas vocais até rugir como os pumas ferozes prontos para o combate, animais built to kill alertas à mudança de ar, concentrados ao ponto extremo de sentir seu próprio sangue esfriar e a língua sibilar, vendo-se rastejando ao sol como lagartos, engolindo de repente invisíveis insetos para digeri-los, assimilá-los até com eles parecer, descobrindo-se dotados de pinças, mandíbulas, élitros que permitem que desloquem enormes massas imaginárias de um lado a outro do palco, mexendo-se assimetricamente sobre seis ou oito patas, trabalhando com vigor até tornarem-se verdadeiros robôs, máquinas elétricas de limpeza a pleno regime programadas para lustrar cada milímetro do piso, a ponto até de limpar invisíveis superfícies verticais, explorando o menor segmento de seu corpomáquina, deslocando-se de qualquer maneira, sem cessar, para que nenhum resíduo de poeira sobreviva à sua passagem, ao preço, em compensação, da disseminaçáo sobre o palco de transparentes gotas de suor, como acontece em cada ensaio.

$\mathrm{O}$ training pode se desenvolver sob outras formas, mas a parte animal/robótica é a que nos interessa mais. $\mathrm{O}$ objetivo do ator de Fabre - diferentemente do ator de teatro dramático de base textual - não é se tornar outro, mas outra coisa. Uma característica essencial do ensaio é a metamorfose ininterrupta, a contínua passagem de um animal a outro, de uma específica qualidade de movimento à sua antítese, de um estado psicofísico particular ao seu contrário (a progressão por oposição, tão simples quanto eficaz, é recorrente no teatro de Fabre). A sessão de trabalho não prevê pausa ou momento de repouso. O movimento contínuo envolve o corpo dos atores, mas, sobretudo, estimula esse corpo, coloca-o à prova da atençáo e da concentração, testando sua perpétua capacidade de adaptaçáo e de resposta aos stimuli lançados. A passagem de um animal a outro não pode ser nem brusca nem automática. "Nos detalhes há um anjo e um demônio" 35 , repete frequentemente o diretor. Músculo após músculo, um membro após o outro, o puma deve se transformar em lagarto. $\mathrm{O}$ eventual espectador quase não deveria perceber o instante em que morre o mamífero e nasce o réptil. $\mathrm{O}$ ator deve atravessar um estado híbrido no qual se misturam sangue quente e sangue frio, deve provocar e, ao mesmo tempo, sofrer a transformaçáo.

Se o corpo orgânico permanece ancorado na sua materialidade, o corpo sottile ${ }^{36}$ irradia além dos seus próprios limites físicos. 
A projeção mental do seu próprio esqueleto, estabelecido em uma conformaçáo corporal diferente (como a do animal), permite alargar a escala normal dos movimentos à disposição do ser humano. Fabre, que guia os atores durante o ensaio, chama atenção para a articulação corporal e, nesse sentido, podem nos voltar ao espírito as palavras do coreógrafo Hubert Godard, que vê nas articulaçóes anatômicas o ponto de partida do movimento: "[...] vejo a articulaçáo como o lugar de uma separaçáo: uma parte do meu corpo permanece minha, uma outra parte se desloca em um espaço ao qual atribuo um sentido, um valor, no qual projeto uma imagem do gesto, construo uma ação virtual" (Godard, 2001, p. 372). O movimento é primeiro imaginado (projetado) e em seguida realizado. A articulação é a potência do movimento, na medida em que é a parte do corpo que dá infinitas possibilidades de deslocamento no espaço tridimensional. O que Godard chama de ficção - a capacidade do dançarino de imaginar sua própria anatomia no espaço - é o verdadeiro motor do movimento. A virtualizaçáo de si permite ao performer (performer de Fabre, no nosso caso) transformar sua própria condição: "[...] quero ver alguém se metamorfosear. Uma metamorfose por autoenvenenamento. Um veneno que faça nascer uma nova vida, a vida artificial em cena" (Fabre, 2012, p. 186). A consciência do performer de seu estado de atuaçáo é fundamental. Cada movimento posto em cena deve ser destinado ao público e concebido com esse efeito: na abertura, legível, interessante.

\section{$\mathbf{X}$}

Entre uma decifração das modificaçóes voluntárias das obras reencenadas, o testemunho de uma variação imprevista obrigada pelas circunstâncias e um esclarecimento sobre a formaçáo de ator, procurei traçar um percurso cognitivo atrás dos bastidores da companhia Troubleyn/Jan Fabre. O resultado pode ser apenas parcial: esta crônica fragmentária não é senão um aperitivo apetitoso que dá vontade de se sentar à mesa do diretor flamenco, para saborear todo o seu banquete. As poucas janelas abertas aqui sobre o trabalho de Fabre são de qualquer modo suficientes para compreender que os estudos genéticos (nesse caso, a presença do pesquisador no local dos ensaios) permitem uma descoberta da obra e do artista muito mais aprofundada e documentada do que somente a análise estética 
de um espetáculo realizado. É, no entanto, evidente que, mesmo perseguindo um percurso lado a lado com os criadores, o objetivo do pesquisador não pode ser a restituiçáo exata de todos os mecanismos que deram origem a um espetáculo, nem as motivações reais na base de cada escolha artística. Quem se encarrega da apaixonante missão de analisar uma obra deve se servir de todas as ferramentas necessárias para realizar seu trabalho, sabendo que não há nenhuma verdade a se atingir, mas muitos documentos/monumentos a desenterrar, pesquisas a realizar, raciocínios a traçar. 


\section{Notas}

${ }^{1}$ No original em francês: "Le théâtre est ailleurs. Il est dans la vie même qui anime la scène et qui fait qu’année après année, spectacle après spectacle, le théâtre ne cesse de se renouveler sans qu'aucune étude n'arrive à le figer ni même à en découvrir les lois fondamentales. C'est cette vie que l'analyse génétique doit chercher à préserver afin d'éviter ces clivages mortels dont toute l'analyse théorique du théâtre porte les stigmates".

${ }^{2}$ Ver, por exemplo, a revista About Performance (University of Sydney) dirigida por Gay McAuley; o número especial de "Genesis" dedicado ao teatro (n. 26, outono 2006), preparado sob a direção de Nathalie Léger e Almuth Grésillon; "Theatre research international”, especial na Genetics of Performance, v. 33, n. 3, out. 2008.

${ }^{3}$ Emprego aqui o adjetivo "líquido" referindo-me ao percurso do acontecimento teatral (dos ensaios à turnê) para indicar um processo indefinível, porque ausente de forma. Naturalmente, pego a metáfora emprestada do sociólogo Zygmunt Bauman, que propôs o termo "modernidade líquida" para descrever o mundo pós-moderno (Bauman, 2000).

${ }^{4}$ No original em italiano: "[...] la scrittura è l'evento finale; finite le repliche, sulla carta vengono 'sublimate' e 'metabolizzate tutte le variazioni possibili, distillate in una forma che sarà quella da consegnare alla memoria” (Monteverdi, 2004, p. 95).

${ }^{5}$ Os primeiros usos do termo estão relacionados a encenações de acontecimentos históricos, práticas inicialmente correntes nos Estados Unidos, que tiveram grande sucesso na segunda metade do século XX, adquirindo tais proporçôes que se tornaram um verdadeiro objeto de estudo a analisar e a relacionar com as artes visuais e performativas (conforme o recente estudo de Rebecca Schneider que relaciona a encenaçáo de acontecimentos de guerra passados com a prática crescente do reenactment em performance (Schneider, 2011).

${ }^{6}$ No original em inglês: "[...] such effect of distancing are rare in reconstruction of historical dance. But reciprocally, the idea of reconstructing the work of a predecessor has been rare, until recently, among contemporary choreographers" (Franko, 1989, p. 56).

${ }^{7}$ No original em inglês: "[...] reconstructing and citing historical dance pieces as well as making the dance stage a site for archiving dance performativity have become major trends in contemporary dance" (Hardt, 2011, p. 27).

${ }^{8}$ Director, scenography, lightdesign: Jan Fabre. Choreography: Jan Fabre, Marc Vanrunxt. Assistancy 1982: Christ Mahy. Assistancy 2012: Miet Martens, Renée Copraij. Costumes: Pol Engels. Actors 1982: Els Deceukelier, Dominique Krut, Eric Raevens, Marc Van Overmeir, Paul Vervoort, Philippe Vansweevelt, Rena Vets, Danny Kenis. Actors 2012: Maria Dafneros, Piet Defranq, Melissa Guerin, Carlijn Koppelmans, Lisa May, Giulia Perelli, GIlles Polet, Pietro Quadrino, Kasper Vanderberghe. Music: Guy Drieghe. Production 1982: Beursschouwburg, Brussels/C.ET. Antwerp. Production 2012: Troubleyn/ Jan Fabre vzw, deSingel, Antwerp (Belgian premiere); Roma Europa festival, Rome.

${ }^{9}$ De macht der theaterlijke dwaasheden (The Power of Theatrical Madness) Director and choreography: Jan Fabre. Costumes: Pol Engels. Dramaturgy: Maart Veldman. Music: Wim Mertens. Actors 1984: Ingrid Dalmeyer, Els Deceukelier, Marion Delforge, Marc Hallemeersch, Roberto de Jonghe, Peter Janssens, Erwin Kokkelhoren, Katinka Maes, 
Annamirl Van der Pluym, David Riley, Werner Strouven. Actors 2012: Maria Dafneros, Piet Defranq, Melissa Guerin, Nelle Hens, Sven Jakir, Carlijn Koppelmans, Georgios Kotsifakis, Dennis Makris, Lisa May, Giulia Perelli, GIlles Polet, Pietro Quadrino, Merel Severs, Nicolas Simeha, Kasper Vanderberghe. Production 1982: Project3, Antwerp/ Stichting Mickery Workshop, Amsterdam/ Kaaitheater, Brussels. Production 2012: Troubleyn/Jan Fabre vzw, deSingel, Antwerp (Belgian premiere); Roma Europa festival, Rome.

${ }^{10}$ Para uma crônica detalhada do processo de criação de Fabre ver Van Den Dries (2004).

${ }^{11}$ Não exatamente graças a sua memória pessoal (pois as performances eram demasiado longas, ricas em detalhes e distantes no tempo para poder nelas acreditar), mas, sobretudo, em função das publicaçóes dos textos dos espetáculos (com notas de deslocamento e gravaçôes de vídeo de baixa qualidade) (Fabre 2009a).

${ }^{12}$ A carreira teatral de Jan Fabre - excluídas suas primeiras performances - começa em 1981 com Theater geschreven met een $K$ is een kater: em cinquenta minutos, quatro atores cosem um tecido de ações reais (não realistas) gerando cenas of ordinary madness: é o corte transversal de um espírito dividido entre o elogio e a recusa da inteligência, o respeito e a ofensa da dignidade humana, o desprezo e o desejo da liberdade animal. A traduçáo francesa Théâtre ecrit avec un $K$ est un matou flamand não faz justiça ao jogo de palavras original: Kater (Theater $+K$ ) em holandês significa gato, mas também ressaca.

${ }^{13}$ No original em inglês: "[...] when I have to choose between anger and technique, I will always choose the one who has anger" (Fabre; Boato, 2012, entrevista).

${ }^{14}$ Para informações mais detalhadas sobre a estrutura logística e operativa da Troubleyn/ Jan Fabre, remetemos ao capítulo dedicado em Duplat (2005).

${ }^{15}$ No original em inglês: "I'm looking for the real anger, 'I want to die for it': they had it natural those days, they were amateurs in the sense that they were lovers of beauty" (Fabre; Boato, 2012, entrevista).

${ }^{16}$ No original em inglês: "I teach my company: the last performance will be the first one" (Fabre; Boato, 2012, entrevista).

${ }^{17}$ No original em inglês: "I change people to make them alert, awake, to not step into the trap of automatism" (Fabre; Boato, 2012, entrevista).

${ }^{18}$ Isso significa que, apesar desse acréscimo, os atores, no entanto, não são nunca mais que oito em cena - como na versão original - exceto o último quadro, no qual estão presentes os nove performers.

19 A estrutura da Troubleyn/Jan Fabre acolhe várias obras de artistas contemporâneos, oferecidas ao diretor ou doadas em troca de outras obras (Scholde, 2007).

${ }^{20}$ No original em inglês: "When I saw it for the first time, I was really moved" (Fabre; Boato, 2012, entrevista).

${ }^{21}$ As razóes são múltiplas, sobretudo a questão do número de atores: Le pouvoir prevê quinze performers, C'est $d u$ théâtre exige oito. Pode-se imaginar que o mês de ensaios de Pouvoir serviu também para o diretor conhecer ulteriormente as qualidades dos atores no trabalho e poder assim melhor definir o elenco de C'est du théâtre. Naturalmente, o elenco 
foi definido apenas no último dia de ensaios. A prova disso é que a decisão final foi adotar nove intérpretes (necessidade que ficou evidente apenas no trabalho em cena).

${ }^{22}$ Compositor belga, em 1984 acompanhou a companhia de Fabre durante o período de ensaios de Pouvoir e compôs as três partes de música minimalista empregadas no espetáculo, posteriormente colocadas em álbum.

${ }^{23}$ Durante os ensaios do reenactment, discutia-se o prolongamento da lista até nossos dias, preenchendo a lacuna dos trinta anos que nos separam do original. Por questóes de fidelidade, foi decidido náo prolongar o catálogo no tempo, mas, ainda assim, solucionar algumas lacunas ou esquecimentos.

${ }^{24}$ Cena quatro: do fim do século XIX até a metade do século XX, do duque de Meiningen até Eugène Ionesco; cena sete: anos 1950 e 1960, de Peter Brook até Botho Strauss; cenas onze e doze: dedicadas à dança do século XX, de Loïe Fuller até Pina Bausch; cena quinze: anos 1970, de Heiner Müller até Lee Breuer.

25 "As convençóes artísticas. As tradições da história da arte (Tenho vontade de estrangulálos enquanto os beijo)" (Fabre, 2012, p. 216).

${ }^{26}$ FABRE, Jan. This is theatre like it was to be expected and foreseen, cena quatro, texto inédito da versão de 2012.

${ }^{27}$ Ator, cenógrafo, diretor, mas, sobretudo, teórico do teatro, Craig chegou a sonhar com uma cena sem atores (preenchida somente por screens, telas móveis que transformariam a cena em uma máquina expressiva nas mãos de seu criador - o diretor), ou de uma cena em que os atores se tornariam über-marionette, corpos perfeitamente dominados pelo pensamento (do ator ele mesmo, mas também do diretor) (Craig, 1971; Attolini, 2008).

${ }^{28}$ No original em francês: "Des personnages, aveuglés par un ruban de sparadrap noir, tenant des perruches au bout d'un fil et disant à tour de rôle, en anglais, flamand, français, allemand, "j’aime la vie”, "je veux rester en vie”, "Bien des amis sont là", "Qui me viendra en aide ?" présentent peut-être la traduction scénique la plus précise qu'on puisse faire d'un voyage aux enfers" (Dumond, 1983, s. p.).

${ }^{29}$ Cursos dirigidos por Renée Copraij: entrou na companhia em 1987 para o balé Das Glas im Kopf wird vom Glas - The dance sections. Copraij trabalhou como performer de Fabre até 1998 (The fin comes a little bit earlier this century - But business as usual). Desde 2002 (Swan Lake), é assistente de dramaturgia e preparadora dos performers para vários espetáculos de Fabre, inclusive para as duas produçóes que eu mesmo acompanhei in loco.

${ }^{30}$ Curso dirigido por um professor de kendo, antigo colega de Fabre: os dois dedicaram-se ao kendo na juventude, depois Fabre tomou outro caminho.

${ }^{31}$ No original em francês: "[...] un metteur en scène doit travailler avec un acteur déjà formé pour inventer une interprétation d'ensemble, et non pallier un manque de formation ou se préoccuper de la progression personnelle d'un individu dans sa carrière théâtrale" (Proust, 2006, p. 63).

32 Informações biográficas obtidas de Fabre, 2012, e de conversas do autor com o diretor. Para mais detalhes sobre esse tema fundamental na obra de Fabre veja Hoet (1993) e Celant (1994). 
${ }^{33} \mathrm{Um}$ dos exemplos mais recentes é a série de esculturas Chapitres I-XVIII que representam o rosto do artista de dezoito maneiras diferentes, cobertas de diversas ramagens: algumas estão em excrescências (do interior para o exterior), outras estão em infiltraçôes do exterior, próteses incrustadas no crânio humano.

${ }^{34}$ No original em francês: "Un lion en cage se déplace exactement au rythme du métronome et repose la patte exactement là où elle était initialement. Cette répétitivité n'est pas le signe d'un être obtus, ni de simple répétitivité, non, c'est le signe d'une constante tension à vivre selon un rythme. [...] Nous définirons l'acteur un "magnifique animal" qui veut montrer son propre art. [...] Le nouveau théâtre naîtra, donc, de l'interaction entre nature et corps humain, ce qui revient à dire de la fusion entre l'Homme et la part animale qu'il a en lui" (Meyerhold, 1993, p. 54).

${ }^{35}$ No original em inglês: "In the detail is the angel and the devil".

${ }^{36}$ Com essa expressão, Silvia Fanti se refere à "[...] tradizione medievale che nomina 'corpo sottile' uno degli strati dell'essere, un doppio ridotto e filiforme, una miniatura del volume fisico di ogni persona" para descrever "un'idea di corpo comune alla nuova generazione dei danzatori che 'non danzano più'". Il loro strumento, il corpo appunto, abbandona i virtuosismi coreografici per una dimensione meno assertiva, meno centrale nell'universo della creazione scenica" (Fanti, 2003, p. 10).

\section{Referências}

ATTOLINI, Giovanni. Teatro Arte Totale: pratica e teoria in Gordon Craig. Bari: Progedit, 2008.

BAUMAN, Zygmunt. Liquid Modernity. Cambridge: Polity, 2000.

CELANT, Germano (Org.). Arti \& Insetti \& Teatri. Genova: Costa \& Nolan, 1994.

CRAIG, Edward Gordon. Il mio Teatro. Milano: Feltrinelli, 1971.

DUMONT, François. Le Temps Mode d'Emploi. Libération, Paris, 27 out. 1983.

DUPLAT, Guy. Une Vague Belge. Bruxelles: Editions Racine, 2005.

FABRE, Jan. C'est du Théâtre comme c'Était à Espérer et à Prévoir. Paris: L’Arche, 2009a.

FABRE, Jan. Le Pouvoir des Folies Théâtrales. Paris: L’Arche, 2009b.

FABRE, Jan; BOATO, Giulio. Entrevista com Jan Fabre por Giulio Boato, em 08 jun. 2012. (Gravação sonora inédita).

FABRE, Jan. Journal de Nuit (1978-1984). Paris: L'Arche, 2012.

FANTI, Silvia (Org.). Il Corpo Sottile. Milão: Ubulibri, 2003.

FÉRAL, Josette. Pour une Analyse Génétique de la Mise en Scène. Théâtre/public, Paris, n. 144, p. 54-59, 1997.

FÉRAL, Josette. Towards a Genetic Study of Performance: Take 2. Theatre Research

International, Austin, v. 33, n. 3, p. 223-233, out. 2008. 
FRANKO, Mark. Repeatability, Reconstruction and Beyond. Theatre Journal, The Johns Hopkins University Press, v. 41, n. 1, p. 56-74, mar. 1989.

GODARD, Hubert. Conversazione con Hubert Godard. In: MENICACCI, Armando, QUINZ, Emanuele (Org.). La Scena Digitale: nuovi media per la danza. Bolzano: Marsilio, 2001, p. 371-381.

HARDT, Yvonne. Staging the Ethnographic of Dance History: contemporary dance and its play with tradition. Dance Research Journal, Cambridge, Cambridge University Press, v. 43, n. 1, p. 27-42, jun. 2011.

HOET, Jan; DE GREEF, Hugo. Gesprekken met Jan Fabre. Louvain: Kritak, 1993.

LAURENT, Anne. Jan Fabre toute une nuit. Liberation, Paris, 24 out. 1983.

LEHMANN, Hans-Thies. Le Théâtre Postdramatique. Paris: L’Arche, 2002.

MERTENS, Wim. Maximizing the Audience. WM, Spain, 1984. 1 Faixa sonora. (1 CD de áudio).

MEYERHOLD, Vsevolod. Ciclo de conferência no período de 6-27/5/1919. In: MEYERHOLD, Vasevolod. L'Attore Biomeccanico. Milano: Ubulibri, 1993. P. 53-56.

MONTEVERDI, Anna Maria. Il Teatro di Robert Lepage. Pisa: Edizioni BFS, 2004.

PROUST, Sophie. La Direction d'Acteurs: dans la mise en scène théâtrale contemporaine. Vic la Gardiole: L'Entretemps ed., 2006.

SCALI, Marion. Des Souris et des Hommes. Nouvel Observateur, Paris, 27 out. 1983.

SCHNEIDER, Rebecca. Performing Remains: Art and War in Times of Theatrical Reenactment. New York: Routledge, 2011.

SCHOLDE, Robert. Achter de Wolken Schijnt de Zon. Obra de arte. Pintura sobre mural, $600 \times 200 \mathrm{~cm}, 2007$.

VAN DEN DRIES, Luk. Corpus Jan Fabre: observaties van een creatieproces. Gent: Van Imschoot, 2004.

Giulio Boato é formado em artes do espetáculo pela Universitá Iuav de Veneza em 2010 e tem mestrado em Performing Studies pela Universitá de Bologna em 2012. É doutorando na Université Paris III Sourbonne Nouvelle sob a orientaçáo de Josette Féral.

E-mail: doyoudada@gmail.com

Traduzido do original em francês por Thiago Mattos de Oliveira sob a supervisão de Dominique Boxus (Universidade Federal Fluminense). Revisado por Márcio Müller.

Recebido em 10 de fevereiro de 2013 Aprovado em 02 de abril de 2013 